\title{
Differential effects of variations in human P450 oxidoreductase on the aromatase activity of CYP19A1 polymorphisms R264C and R264H
}

\author{
Shaheena Parween ${ }^{1,2}$, Giovanna DiNardo ${ }^{3}$, Francesca Baj ${ }^{1,2,3}$, Chao Zhang ${ }^{3}$, Gianfranco Gilardi ${ }^{3, *}$, \\ and Amit V. Pandey ${ }^{1,2 *}$
${ }^{1}$ Pediatric Endocrinology, Diabetology, and Metabolism, Department of Pediatrics, University Children's Hospital Bern, 3010, Bern, Switzerland. ${ }^{2}$ Department of Biomedical Research, University of Bern, 3010 Bern, Switzerland.
${ }^{3}$ Department of Life Sciences and Systems Biology, University of Torino, Via Accademia Albertina 13, Torino, Italy

\section{* Correspondence:}

PD Dr. Amit V Pandey: Pediatric Endocrinology, Diabetology \& Metabolism, KIKL C837, University Children's Hospital Bern, Freiburgstrasse 15, 3010 Bern Switzerland

Tel: +41316329637 Email: amit@pandeylab.org

Prof. Gianfranco Gilardi: Department of Life Sciences and Systems Biology, University of Torino, Via Accademia Albertina 13, Torino, Italy. Tel: +39 0116704593 Email: gianfranco.gilardi@ unito.it

Abstract: Aromatase (CYP19A1) converts androgens into estrogens and is required for female sexual development and growth and development in both sexes. CYP19A1 is a member of cytochrome P450 family of heme-thiolate monooxygenases located in the endoplasmic reticulum and depends on reducing equivalents from the reduced nicotinamide adenine dinucleotide phosphate via the cytochrome $\mathrm{P} 450$ oxidoreductase coded by POR. Both the CYP19A1 and POR genes are highly polymorphic, and mutations in both these genes are linked to disorders of steroid biosynthesis. We have previously shown that R264C and R264H mutations in CYP19A1, as well as mutations in POR, result in a reduction of CYP19A1 activity. The R264C is a common polymorphic variant of CYP19A1, with high frequency in Asian and African populations. Polymorphic alleles of $P O R$ are found in all populations studied so far and, therefore, may influence activities of CYP19A1 allelic variants. So far, effects of variations in POR on enzymatic activities of allelic variants of CYP19A1 or any other steroid metabolizing cytochrome P450 proteins have not been studied. Here we are reporting the effects of three POR variants on the aromatase activities of two CYP19A1 variants, R264C and R264H. We used bacterially expressed and purified preparations of WT and variant forms of CYP19A1 and POR and constructed liposomes with embedded CYP19A1 and POR proteins and assayed the CYP19A1 activities using radiolabeled androstenedione as a substrate. With the WT-POR as a redox partner, the R264C-CYP19A1 showed only $15 \%$ of aromatase activity, but the R264H had $87 \%$ of aromatase activity compared to WT-CYP19A1. With P284LPOR as a redox partner, R264C-CYP19A1 lost all activity but retained 6.7\% of activity when P284T-POR was used as a redox partner. The R264H-CYP19A1 showed low activities with both the POR-P284L as well as the POR-P284T. When the POR-Y607C was used as a redox partner, the R264C-CYP19A1 retained around 5\% of CYP19A1 activity. Remarkably, The R264H-CYP19A1 had more than three-fold higher activity compared to WT-CYP19A1 when the POR-Y607C was used as the redox partner, pointing towards a beneficial effect. The slight increase in activity of R264CCYP19A1 with the P284T-POR and the three-fold increase in activity of the R264H-CYP19A1 with the Y607C-POR point towards a conformational effect and role of protein-protein interaction governed by the R264C and R264H substitutions in the CYP19A1 as well as P284L, P284T and Y607C variants of POR. These studies demonstrate that the allelic variants of $\mathrm{P} 450$ when present with a variant form of POR may show different activities, and combined effects of variations in both the P450 enzymes as well as in the POR should be considered when genetic data are available. Recent trends in the whole-exome and whole-genome sequencing as diagnostic tools will permit combined evaluation of variations in multiple genes that are interdependent and may guide treatment options by adjusting therapeutic interventions based on laboratory analysis.

Keywords: CYP19A1; Aromatase; P450 oxidoreductase; estrogen synthase;POR; cytochrome P450.

\section{$1 \quad$ Introduction}

Aromatase (CYP19A1, EC: 1.14.14.14) regulates estrogen biosynthesis [1] by converting androgens into estrogens [2, 3]. CYP19A1 is a 503 amino acid protein (NP_000094) encoded by the CYP19A1 gene (GeneID:1588, NCBI: NM_000103), located on chromosome 15 (15q21.2, GRCh38 15:51208056-51338597). CYP19A1 is a membrane-bound protein located in the endoplasmic reticulum (ER) and is a member of the 
cytochrome P450 superfamily. Cytochrome P450 enzymes are involved in the biosynthesis of steroid hormones, and they also metabolize drugs and xenobiotics [4]. Two different types of the cytochrome P450 family of proteins are present in humans [5]. The P450 type 1 proteins are found in the mitochondrion and are responsible for the metabolism of steroid hormones and sterols and are targets for drugs in a range of disorders [6-11]. The P450 type 2 proteins are localized in the endoplasmic reticulum and have a range of metabolic activities, including drugs, xenobiotics as well as endogenous substrates, and steroid hormones like progesterone, dehydroepiandrosterone, and testosterone [12-17]. Genetic defects in steroid metabolizing cytochromes P450 and their redox partners cause metabolic disorders with disordered steroidogenesis [18-25]. CYP19A1 is highly expressed in ovaries and plays a significant role in the regulation of the reproductive cycle in females [26]. In males, CYP19A1 is expressed in the gonads, and the paracrine effects of CYP19A1 reaction products are required for normal spermatogenesis [27-30].

Additionally, CYP19A1 expression is also found in extra-gonadal tissues, including liver, muscle, placenta, bone, breast, adipose tissue, and brain [26, 31, 32]. Initial work on the characterization of CYP19A1 was done on enzyme preparations purified from the placenta by laboratories of Hall [33], Vickery [34], and Harada [35] and a placental protein preparation was also used for the determination of X-ray crystal structure of CYP19A1 protein by Ghosh [36]. The CYP19A1 protein is required for the biosynthesis of estrogens (C18 steroids) from the androgen precursors (C19 steroids) [1, 37]. Some of the critical reactions catalyzed by CYP19A1 include the biosynthesis of estrone (E1) from androstenedione, estriol (E3) from 16hydroxytestosterone and 17 $\beta$-estradiol (E2) from testosterone (Figure 1) [1]. The androstenedione and testosterone are well known as the most common physiological steroid substrates for CYP19A1 [1, 38, 39]. Recently 16 $\beta-\mathrm{OH}$-androstenedione was also reported to be a substrate for CYP19A1 [40]. The catalytic process of aromatization of androgens is multifaceted, and it comprises of three enzymatic reaction steps involving the transfer of three pairs of electrons from the co-factor reduced nicotinamide adenine dinucleotide phosphate (NADPH) and consumption of oxygen. Electron transfer from NADPH to CYP19A1 is carried out by NADPH cytochrome P450 oxidoreductase (POR) [41, 42]. The initial two steps of aromatase reaction are two sequential hydroxylation reactions at the 19-methyl group of androgens, whereas the last step causes the aromatization of the A-ring of the steroid, which is specific for CYP19A1 [43-45].

Multiple genetic defects are associated with the reduced CYP19A1 activity in humans (OMIM: 107910, $613546,139300)[19,46]$. In females, a reduction in CYP19A1 activity causes abnormal external genitalia in the female fetus, maternal virilization during gestation, healthy development of ovaries but the increased occurrence of polycystic ovary syndrome, and virilization at puberty [31, 38]. The first case of CYP19A1 deficiency in humans was described by Shozu et al. [2]. Later Morishima et al. described that CYP19A1 deficiency occurs during fetal life in both males and females [47]. Effect of CYP19A1 deficiency on the maturation of skeleton, growth, and bone homeostasis [27, 48], as well as abnormal plasma lipid profile and variations in insulin resistance, have been reported in multiple publications [19, 30, 31, 38, 49-52]. Estrogen excess has also been shown in many publications to cause an increase in the expression and activity of CYP19A1 [53, 54]. Several natural compounds, including nicotine, vitamin E, resveratrol and curcumin, may inhibit CYP19A1 activity [8, 55, 56]. CYP19A1 activity is also inhibited by bisphenol A and sildenafil [55]. CYP19A1 inhibitors like anastrozole are used in the treatment of breast cancer and to treat the excess production of estrogen in men [57].

POR deficiency (PORD, OMIM: 613537 and 201750), is a rare form of congenital adrenal hyperplasia, that was first reported in patients with disordered steroidogenesis [24], and later on, multiple disorders have been linked to mutations in POR [42, 58-61]. While many cytochromes P450 have been tested with different POR variants, allelic variants of the steroid metabolizing cytochromes P450 have not been studied for the potential changes in enzyme activities caused by variant forms of POR [42, 60, 62]. Subramanian et al. had examined the combined effect of P450 and POR variations in a report describing activities of three common alleles of CYP2C9 assayed with the WT and variant forms of POR [63]. Since POR is obligate electron donor for all cytochrome P450 proteins in the endoplasmic reticulum, variations in POR should also be taken into account when studying the effect of genetic polymorphisms in cytochromes P450. Loss of CYP19A1 activity 
may severely affect the production of estrogens, and several variations of POR exist with significant population distribution, which can alter enzymatic activities of CYP19A1 [64-68]. We, therefore, tested the impact of some population variants of POR on estrogen formation by the two variants of CYP19A1. The R264C (rs700519) is a common polymorphic variant of CYP19A1(CYP19A1*4) while the R264H (rs2304462) is a rare variant. We generated the WT and variant forms of human POR and CYP19A1 in bacteria and used lipidbased reconstitution to do the enzymatic analysis of CYP19A1-aromatase activity using androstenedione as a substrate. We also studied the effect of CYP19A1 variations on protein stability by limited proteolysis to understand the potential causes of the changes in enzyme activities by different variants. This study shows that variations in POR may have variable effects on activities of CYP19A1 variants, potentially leading to altered steroid metabolism in individuals with variant CYP19A1 alleles.

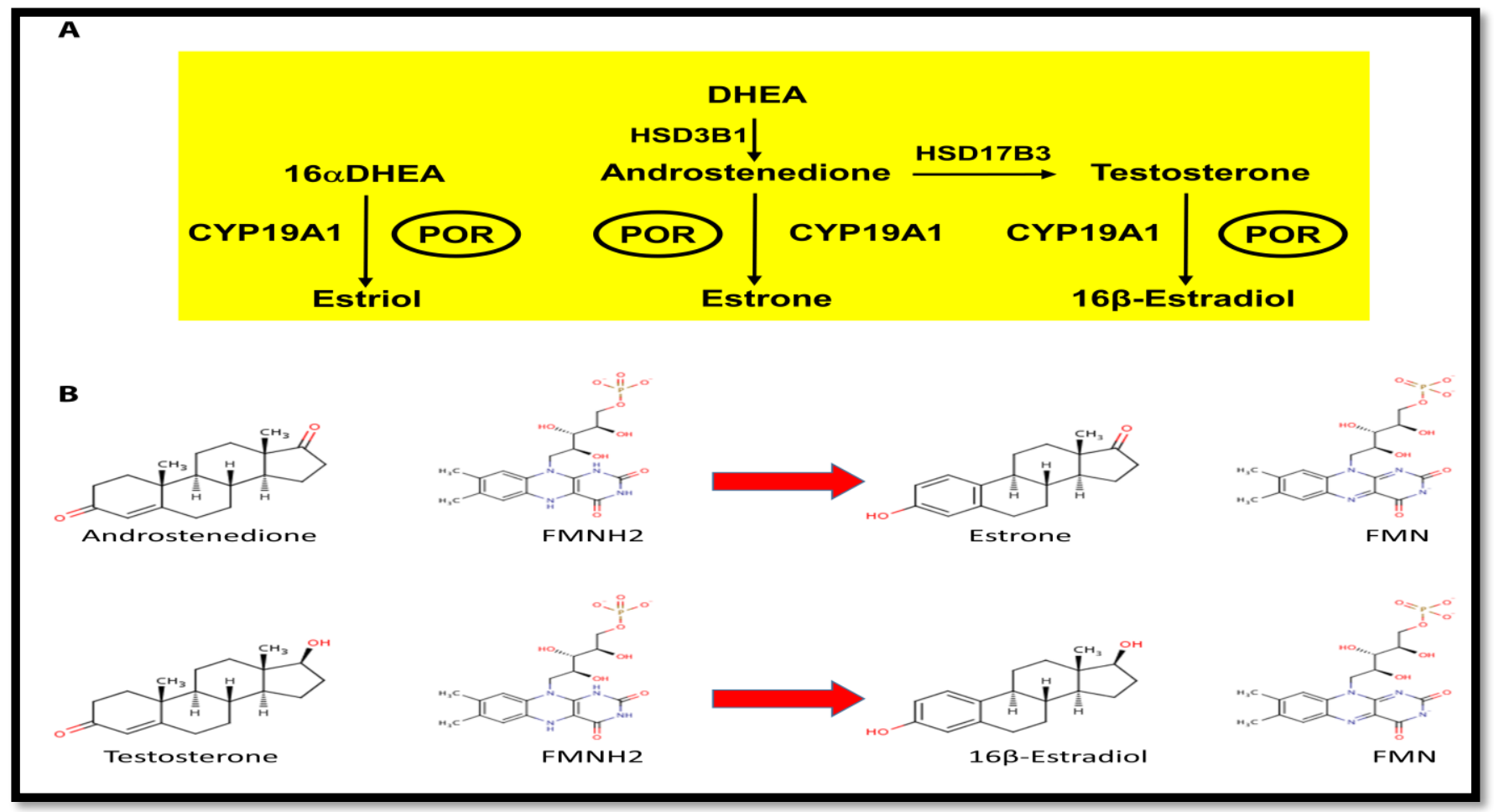

Figure 1: Steroid hormone biosynthesis and role of POR. A: In the human placenta, DHEA (CHEBI:28689) is metabolized to form androstenedione. Androstenedione then serves as a substrate for the formation of testosterone (CHEBI:17347) which is then converted into estrogens. In the liver of the fetus, DHEAS (CHEBI:16814) is metabolized into 16 $\alpha$ DHEAS (CHEBI:87774), which then gets converted into 16 $\alpha$ DHEA inside the placenta to form estriol (CHEBI:27978). The biosynthesis of estrogens requires the aromatase activity of CYP19A1, which is reliant on POR. Figure adapted from our previous publication by Udhane et al. 2017 [64]. B: Electron transfer from NADPH to CYP19A1 is carried out via POR through reduced FAD and FMN. Chemical structures were obtained from ChEBI (https://www.ebi.ac.uk/chebi/).

\section{Materials and methods}

Materials: Tris-base, NADPH, acetic acid, dyes were from LI-COR Bioscience Inc. (NE, USA). magnesium acetate, Sucrose, potassium phosphate The protein assay dye reagent (RC-DC assay) was EDTA, DTT, glycerol, PMSF, and Benzonase were from Bio-Rad (Hercules, CA). The anti-POR purchased from Sigma-Aldrich Chemie $\mathrm{GmbH}$ (Buchs, Switzerland). Carbenicillin, $\mathrm{FeCl}_{3}, \mathrm{ZnCl}_{2}$, $\mathrm{CoCl}_{2}, \mathrm{Na}_{2} \mathrm{MoO}_{4}, \mathrm{CaCl}_{2}, \mathrm{CuCl}_{2}, \mathrm{M} \mathrm{H}_{3} \mathrm{BO}_{3}$ were purchased from CarlRoth $\mathrm{GmBH}$ (Switzerland). Goat anti-rabbit antibodies labeled with infra-red antibody was from Genscript (NJ, USA).

Recombinant expression and purification of CYP19A1 and its polymorphic variants $\mathbf{R} 264 \mathrm{H}$ and R264C. The experiments were carried out with 
a well-characterized recombinant soluble human CYP19A1, which has the structure and activity comparable to full-length CYP19A1 [69]. The polymorphic variants $\mathrm{R} 264 \mathrm{H}$ and $\mathrm{R} 264 \mathrm{C}$ of CYP19A1 were generated as described previously by Baravalle et al. in 2017 [70]. The WT CYP19A1 and the two polymorphic variants, $\mathrm{R} 264 \mathrm{H}$ and R264C, were expressed and purified based on previously described methods [69, 71-73]. Briefly, the $E$. coli $\mathrm{DH} 5 \alpha$ rubidium-competent cells were transformed with a pCWOrit plasmid vector carrying the CYP19A1 gene and selected with 100 $\mu \mathrm{g} / \mathrm{mL}$ ampicillin. The CYP19A1 protein expression was induced by the addition of $1 \mathrm{mM}$ Isopropyl $\quad \beta$-D-1-thiogalactopyranoside. Liquid cultures were grown in the Terrific Broth medium in the presence of the heme precursor $\delta$ aminolevulinic acid at $28^{\circ} \mathrm{C}$ for 48 hours. Bacterial cells were collected and re-suspended in $100 \mathrm{mM}$ potassium phosphate $(\mathrm{pH}$ 7.4) containing $20 \%$ glycerol, $1 \%$ Tween-20, and $1 \mathrm{mM} \quad \beta$ mercaptoethanol supplemented with $1 \mathrm{mg} / \mathrm{mL}$ lysozyme and a protease inhibitor cocktail (Roche, Switzerland) at $4^{\circ} \mathrm{C}$. Bacteria were broken by sonication and ultra-centrifuged at $100000 \mathrm{x} \mathrm{g}$ for 20 minutes. The cellular supernatant containing the soluble proteins was loaded on an ion-exchange column (DEAE-Sepharose Fast-Flow, GE Healthcare), followed by processing over a Nickelion Chelating-Sepharose Fast-Flow affinity column (GE Healthcare). The CYP19A1 protein was eluted from the Nickel-Sepharose column with a gradient of $1 \mathrm{mM}$ to $40 \mathrm{mM}$ histidine, which was later removed by ultrafiltration on the $30 \mathrm{kD}$ molecular weight cut-off Amicon concentrator device (MerckMillipore).

POR expression and membrane purification: The WT POR and variants were produced in bacteria using the plasmid constructs described in earlier publications [68, 74-76]. The protocol for the expression of POR variants and membrane as well as liposome preparation is reported in our earlier publications [64-66, 68, 74, 77].

CYP19A1 activity measurement in the reconstituted liposome system. CYP19A1 activity of proteins was monitored by the tritiated water release assay based on an earlier method described by Lephart and Simpson [78] with slight modifications that have been described previously using an assay system containing lipids, POR and CYP19A1 [64, 68]. Androstenedione was used as the substrate for the CYP19A1 reaction. POR and CYP19A1 proteins were mixed into liposomes containing 1,2-Dilauroyl-sn-glycero-3phosphorylcholine (DLPC) and 1,2-Dilauroyl-snglycero-3-phosphorylglycerol (DLPG). Reaction mixture consisted of 50 pmol of CYP19A1, 200 pmol of POR and 20,000 cpm of ${ }^{3} \mathrm{H}$ androstenedione $\quad\left(\left[1_{-}{ }^{3} \mathrm{H}(\mathrm{N})\right]\right.$-andros-tene-3,17dione;) in $100 \mathrm{mM}$ potassium phosphate buffer ( $\mathrm{pH}$ 7.4) with $100 \mathrm{mM} \mathrm{NaCl}$. Different concentrations of androstenedione $(0.01-30 \mu \mathrm{M})$ were used for assays to study the enzyme kinetics. The enzymatic reaction of CYP19A1 was started by adding $\mathrm{NADPH}$ to $1 \mathrm{mM}$ concentration, and reaction mixtures were incubated with shaking for $1 \mathrm{~h}$. The reaction was stopped by adding chloroform and the water phase was mixed with a $5 \%$ charcoal $/ 0.5 \%$ dextran solution and centrifuged at $14000 \mathrm{x}$ g for 5 minutes and $0.5 \mathrm{ml}$ of supernatant was used for ${ }^{3} \mathrm{H}$ radioactivity counting. The specific activity of human CYP19A1 was calculated as (pmol of product/minute of incubation/nmol of $\mathrm{P} 450$ ), where pmol of the product formations were calculated as:

[cpm $\left.\mathrm{cpmple}_{\text {samp }}-\mathrm{cpm}_{\text {blank }}\right] \cdot$ pmol of cold androstenedione/total cpm

Data were analyzed using GraphPad Prism (GraphPad, La Jolla, CA) based on MichaelisMenten kinetics to determine the Vmax and $\mathrm{Km}$. Values obtained from triplicate experiments were expressed as mean \pm S.E.M. (standard error of mean).

FASTpp assay of CYP19A1 and its polymorphic variants $\mathbf{R} 264 \mathrm{H}$ and $\mathbf{R} 264 \mathrm{C}$ : The FASTpp assay was performed as described previously $[66,79,80]$. Reaction mixtures contained $0.2 \mathrm{mg} / \mathrm{mL}$ of CYP19A1 WT or polymorphic variants R264H and $\mathrm{R} 264 \mathrm{C}, 10 \mathrm{mM} \mathrm{CaCl} 2,0.05 \mathrm{mg} / \mathrm{mL}$ thermolysin in $0.1 \mathrm{M}$ potassium phosphate buffer $(\mathrm{pH}$ 7.4) containing $20 \%$ glycerol, $0.1 \%$ Tween-20, and 1 $\mathrm{mM} \beta$-mercaptoethanol. A negative control reaction was carried out without including thermolysin. Protein digestion was performed for one minute in 
a TGradient Thermoblock (Biometra, Switzerland), generating a temperature gradient from 30 to $70^{\circ} \mathrm{C}$, and reactions were stopped by addition of $10 \mathrm{mM}$
EDTA (pH 8.0). Samples were analyzed by SDSPAGE and quantified using Image Lab software (Bio-Rad, Hercules, CA).

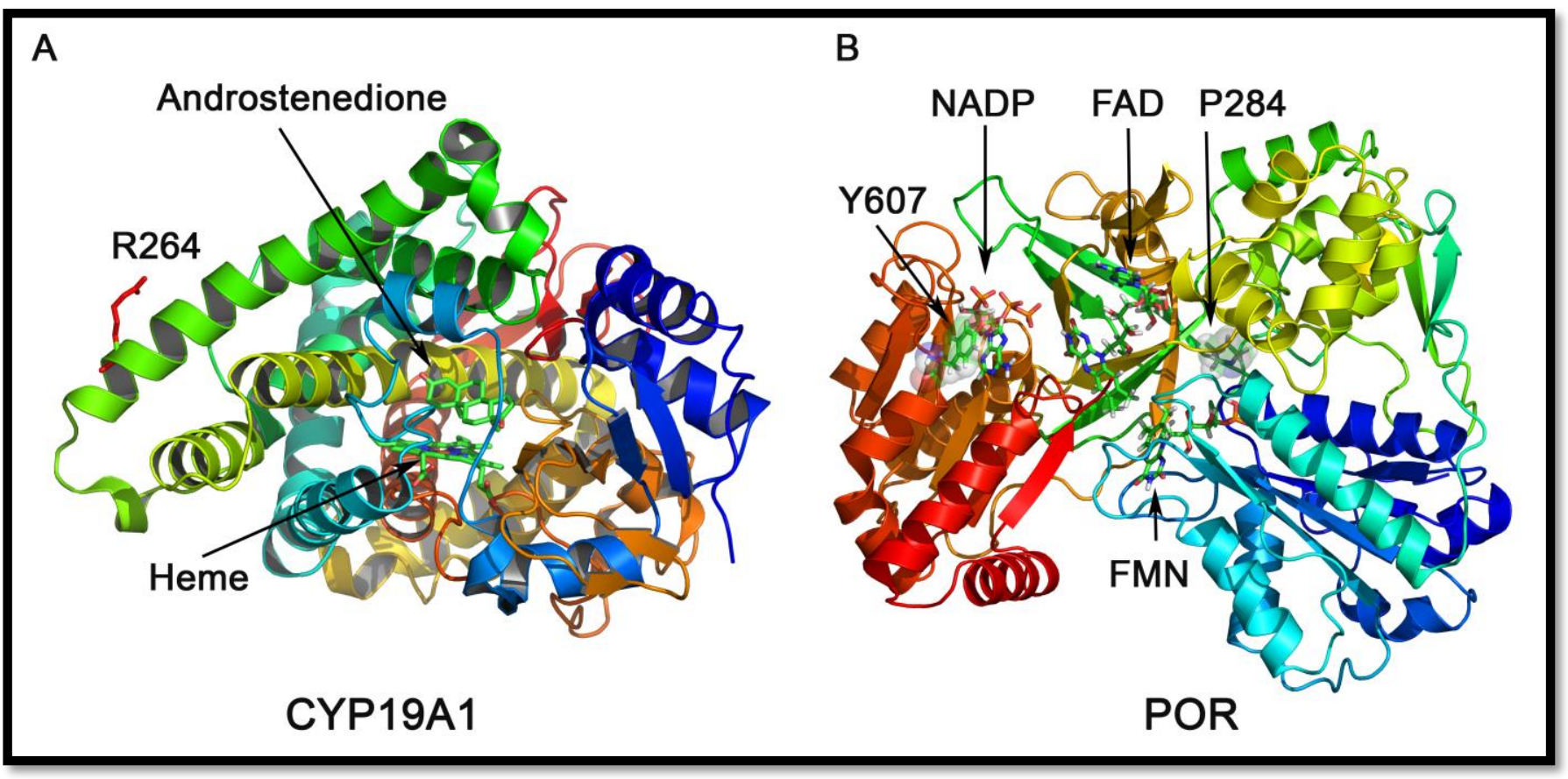

Figure 2: Location of CYP19A1 and POR variants: A. Locations of CYP19A1 variants in protein structure. The R264 residue on CYP19A1 is surface exposed and located on the $G$ helix of the CYP19A1 structure, which is part of the substrate access channel, and it has been widely reported to be flexible in cytochromes P450. Here a ribbons model of CYP19A1 protein is shown, and the bound substrate, androstenedione, is depicted as sticks model. B. Locations of POR variants. X-ray crystal structure of the human POR (PDB\#3QE2) depicting the positions of POR variations described in this study. The co-factors FAD, FMN, and NADP are depicted as sticks. The P284 residue is situated in the hinge region of the POR. The hinge region of POR is vital for flexibility and conformation shifts in POR, and mutations in this region of POR may create changes in conformation that would modify the interactions of POR with its partner proteins. The Y607 residue is located in the NADPH binding site of POR. Binding of NADPH is required for the transfer of electrons to redox partners of POR as well as direct reduction of dyes and small molecules by POR

\section{Results}

Population Genetics of CYP19A1 amino acid variants $\mathrm{R} 264 \mathrm{C}$ and $\mathrm{R} 264 \mathrm{H}$

The R264C variant of CYP19A1 is present at a low frequency in the European population with a minor allele frequency (MAF) of 0.02 in the 1000 Genomes database (Table 1). Among the American population, the MAF of R264C was 0.04. In the East Asian (MAF 0.17), South East Asian (MAF 0.24), and African (MAF 0.18) populations, the R264C variant was present at a much higher frequency. Looking individually, the Italian population from Tuscany had the lowest occurrence of R264C with a MAF of 0.006 in the HapMap database (Table 1). In the HapMap database, the R264C variant was found in a Mexican population with a MAF of 0.01 , while the Japanese population showed the highest presence of R264C with a MAF of 0.27. HapMap data showed similar MAF among subpopulations as reported in 1000 Genome database, the only exception being the Maasai population from Kenya, which had the R264C allele present at the MAF of 0.04, which is much lower than the distribution seen in other African populations. On the other hand, the R264H variant of CYP19A1 (rs2304462) is found only as a rare variant present at a MAF of 0.00003 in ExAc Aggregated Populations and at a MAF of 0.00002 in gnomAD-Exomes. 
Table 1: Genetic data for the CYP19A1 variations. The R264C (DBSNP: rs700519) is a common polymorphism in the CYP19A1 gene. Population codes referred to in the table are for $\mathbf{1 0 0 0}$ Genome: AMR American; AFR African; EAS East Asian; SAS South East Asian; EUR European. For the HapMap project: ASW, African ancestry in Southwest USA; CEU, Utah residents with Northern and Western European ancestry; CHB, Han Chinese in Beijing, China; CHD, Chinese in Metropolitan Denver, Colorado; GIH, Gujarati Indians in Houston, Texas; JPT, Japanese in Tokyo, Japan; LWK, Luhya in Webuye, Kenya; MEX, Mexican ancestry in Los Angeles, California, USA; MKK, Maasai in Kinyawa, Kenya; TSI, Toscans in Italy; YRI, Yoruba in Ibadan, Nigeria. The R264H (rs2304462) is a rare variant and has been seen with lower frequencies across populations. Data for population genetic distribution of variants were retrieved from the NCBI (http://www.ncbi.nlm.nih.gov). Populations with a minor allele frequency that is significantly higher than average are shown in bold.

\begin{tabular}{|l|l|l|l|}
\hline Population ID-Class & $\begin{array}{l}\text { Number of } \\
\text { alleles }\end{array}$ & Major Allele Freq. & Minor Allele Freq. \\
\hline R264C (rs700519 ) & & & \\
\hline 1000 Genome & 5008 & $\mathrm{G}=0.860$ & $\mathrm{~A}=0.140$ \\
\hline 1000 Genome- AMR & 694 & $\mathrm{G}=0.96109998$ & $\mathrm{~A}=0.03890000$ \\
\hline 1000 Genome-AFR & 1322 & $\mathrm{G}=0.81770003$ & $\mathrm{~A}=0.18230000$ \\
\hline 1000 Genome-EAS & 1008 & $\mathrm{G}=0.82940000$ & $\mathrm{~A}=0.17060000$ \\
\hline 1000 Genome-SAS & 978 & $\mathrm{G}=0.76279998$ & $\mathbf{A}=\mathbf{0 . 2 3 7 2 0 0 0 1}$ \\
\hline 1000 Genome-EUR & 1006 & $\mathrm{G}=0.97119999$ & $\mathrm{~A}=0.02880000$ \\
\hline & & & \\
\hline ESP-cohort North America & 4542 & $\mathrm{G}=0.91391456$ & $\mathrm{~A}=0.08608542$ \\
\hline & & & \\
\hline HapMap & & & \\
\hline HapMap-CEU & 224 & $\mathrm{G}=0.96875000$ & $\mathrm{~A}=0.03125000$ \\
\hline HapMap -TSI & 174 & $\mathrm{G}=0.99425286$ & $\mathrm{~A}=0.00574713$ \\
\hline HapMap -MEX & 98 & $\mathrm{G}=0.98979592$ & $\mathrm{~A}=0.01020408$ \\
\hline HapMap -CHD & 170 & $\mathrm{G}=0.88235295$ & $\mathrm{~A}=0.11764706$ \\
\hline HapMap -JPT & 172 & $\mathrm{G}=0.72674417$ & $\mathbf{A}=\mathbf{0 . 2 7 3 2 5 5 8 3}$ \\
\hline HapMap -ASW & 98 & $\mathrm{G}=0.83673471$ & $\mathrm{~A}=0.16326530$ \\
\hline HapMap -GIH & 174 & $\mathrm{G}=0.83908045$ & $\mathrm{~A}=0.16091955$ \\
\hline HapMap -CHB & 82 & $\mathrm{G}=0.85365856$ & $\mathrm{~A}=0.14634146$ \\
\hline HapMap -YRI & 224 & $\mathrm{G}=0.78571427$ & $\mathbf{A}=\mathbf{0 . 2 1 4 2 8 5 7 2}$ \\
\hline HapMap -LWK & 180 & $\mathrm{G}=0.88888890$ & $\mathrm{~A}=0.11111111$ \\
\hline HapMap -MKK & 286 & $\mathrm{G}=0.95804197$ & $\mathrm{~A}=0.04195804$ \\
\hline & & & \\
\hline R264H (rs2304462) & & & $\mathrm{T}=0.00003296$ \\
\hline $\begin{array}{l}\text { ExAc } \\
\text { Populations }\end{array}$ & 121366 & $\mathrm{C}=0.99996704$ & $\mathrm{~T}=0.00002$ \\
\hline gnomAD-Exomes & 246062 & $\mathrm{C}=0.99998$ & \\
\hline
\end{tabular}

\section{Genetics of variants in POR}

The POR variants described in this study were selected by searching the genetic sequence databases. Selected variants were subjected to stability analysis on protein structure followed by sequence conservation studies to filter the variants with disease-causing possibilities [59]. Human POR protein has 680 amino acids and has evolved from the ferredoxin reductase and ferredoxin like structures to create a single $\mathrm{P} 450$ reductase protein in higher eukaryotes [81]. The POR variations described here are highly conserved among different species and are described as rare genetic variants in the Exome database of NCBI (Table 2).
The $\mathrm{P} 284 \mathrm{~L}$ is a rare variant found mostly in Europeans, and the P284T variant had been only observed in an African population [64, 82, 83]. The Y607C is a rare genetic variant found in both the Asian and European populations (Table 2).

\section{Structure analysis of variants in CYP19A1 and POR}

The R264 residue on CYP19A1 is surface exposed and located on the $\mathrm{G}$ helix of the CYP19A1 structure (Figure 2A), which is part of the substrate access channel, and it has been widely reported to be flexible in cytochromes P450. R264 is the central residue of a 3 Arg-containing cluster that is known as a consensus 
sequence for multiple kinases. Thus, it can play a located in the hinge region may cause conformational central role in both the formation of substrate access changes that would change the interactions between and CYP19A1 activity by post-translational POR and its protein/small molecule partners [42, 64]. modifications (51). The amino acid P284 is situated The Y607 residue is located close to the NADPH in the flexible hinge region, between the FAD and binding site (Figure 2B), and the Y607C variant in FMN binding domains of POR (Figure 2B). This POR has been shown to reduce the CYP19A1 hinge region is responsible for flexibility and domain catalytic efficiency by $90 \%$ [65].

movements in POR. Mutations in the POR that are

Table 2: Minor allele Frequencies of variants in POR described in this study according to the Exome database of NCBI.

\begin{tabular}{lclllll}
\cline { 3 - 7 } POR & DBSNP id & Global & European & Asian & American & African \\
P284L & rs72557938 & $\mathrm{T}=0.00005$ & $\mathrm{~T}=0.00004$ & $\mathrm{~T}=0.0001$ & $\mathrm{~T}=0.0000$ & $\mathrm{~T}=0.0000$ \\
P284T & rs72557937 & $\mathrm{A}=0.00004$ & $\mathrm{~A}=0.00000$ & $\mathrm{~A}=0.0000$ & $\mathrm{~A}=0.0000$ & $\mathrm{~A}=0.0005$ \\
Y607C & rs72557954 & $\mathrm{G}=0.00011$ & $\mathrm{G}=0.00008$ & $\mathrm{G}=0.0003$ & $\mathrm{G}=0.0000$ & $\mathrm{G}=0.0000$ \\
\hline
\end{tabular}

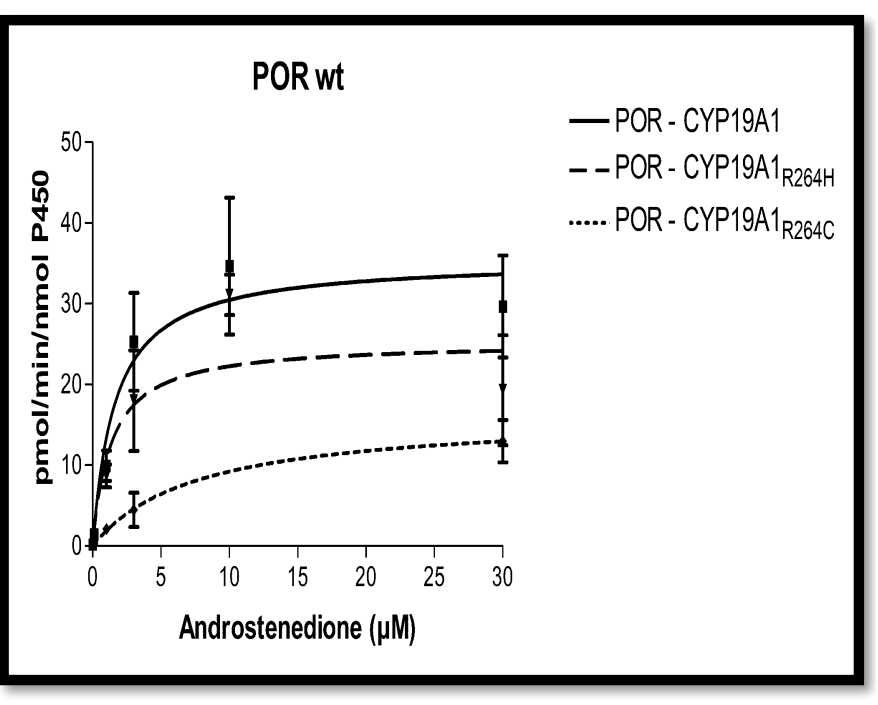

Figure 3: Aromatase activity of CYP19A1 variants with WT-POR. CYP19A1 wild type (solid line) and mutants CYP19A1 $1_{\mathrm{R} 264 \mathrm{H}}$ (dashed line) and CYP19A1 $1_{\mathrm{R} 264 \mathrm{C}}$ (dasheddotted line) activities supported by POR-WT were tested to compare the activities of three different types of CYP19A1 variants. Recombinant preparations of purified human CYP19A1 (WT and variants) expressed in bacteria and recombinant human POR were combined into liposomes. CYP19A1 activity to biotransform androstenedione $\left({ }^{3} \mathrm{H}\right.$ labeled) to estrone was measured by monitoring the release of tritiated water. Data are shown as mean \pm SEM of three independent replicates. Data were fitted using GraphPad Prism, according to the Michaelis-Menten kinetics model. The $\mathrm{K}_{\mathrm{m}}$ and $\mathrm{V}_{\max }$ values calculated from these assays and statistical analysis are given in Table 3.
Enzyme activity of CYP19A1 and its polymorphic variants $\mathrm{R} 264 \mathrm{H}$ and $\mathrm{R} 264 \mathrm{C}$ supported by POR-WT

We performed in-vitro CYP19A1 activity assays with the WT CYP19A1 and its polymorphic variants (R264H and R264C) to study the effects of the two variations on the enzyme activity. To this aim, reconstituted liposomes were prepared by mixing the purified recombinant CYP19A1 with purified membranes containing WT-POR as described in materials and methods. Then we assessed the enzyme activity by standard tritiated water release assay. For the $\mathrm{R} 264 \mathrm{H}$ variant of CYP19A1, the apparent $\mathrm{Km}$ for androstenedione was comparable to that of WT CYP19A1, whereas the apparent Vmax was reduced by $\sim 30 \%$ (Figure 3, Table 3). The catalytic efficiency of the CYP19A1-R264H variant was reduced by $\sim 13 \%$ compared to WT CYP19A1. However, for the R264C variant of CYP19A1, the apparent $\mathrm{Km}$ for androstenedione increased by 3.2 fold as compared to WT CYP19A1. The apparent Vmax was reduced by $\sim 50 \%$.

Therefore, the CYP19A1-R264C variant showed a seven-fold reduction in catalytic efficiency (Vmax/Km) with only $15 \%$ of the residual CYP19A1 activity as compared to WT CYP19A1 (Figure 3, Table 3). This loss of catalytic 
efficiency indicates that R264C mutation of CYP19A1 affects either the interaction of the substrate with CYP19A1 or the CYP19A1-POR interaction, which may influence electron transfer from POR to CYP19A1 for metabolic reactions.

Table 3. Kinetic parameters for activities of CYP19A1 and its polymorphic variants supported by WT POR. Variable androstenedione concentration $(0.3-30 \mu \mathrm{M})$ were used for the biotransformation of androstenedione into estrone. All assays were performed with $1 \mathrm{mM}$ NADPH. Data are shown as mean \pm SEM of independent replicates $(n=3)$. Catalytic efficiencies of different combinations of POR and CYP19A1 variants are given as a percentage of WT-POR and WT-CYP19A1 combination (\% of WT-WT catalytic efficiency). * indicates the significance based on two tailed students t-test $\left({ }^{*} \mathrm{p}<0.05\right)$.

\begin{tabular}{|c|c|c|c|c|}
\hline & $\begin{array}{c}\text { Km Androstenedione } \\
(\mu \mathrm{M})\end{array}$ & $\begin{array}{c}\text { Vmax } \\
\mathrm{pmol} / \mathrm{min} / \mathrm{nmol}\end{array}$ & Vmax/Km & $\begin{array}{c}\% \text { of WT- } \\
\text { WT } \\
\text { catalytic } \\
\text { efficiency }\end{array}$ \\
\hline \multicolumn{5}{|c|}{ CYP19A1 (aromatase) activity for the Conversion of androstenedione to estrone } \\
\hline CYP19A1-WT & $1.6 \pm 0.9$ & $35.5 \pm 4.7$ & 21.6 & 100.0 \\
\hline CYP19A1-R264H & $1.3 \pm 0.9$ & $25.2 \pm 4.1$ & 18.8 & 87.0 \\
\hline CYP19A1-R264C & $5.1 \pm 2.6$ & $16.9 \pm 2.8^{*}$ & $3.3 *$ & $15.3 *$ \\
\hline
\end{tabular}

Table 4. Kinetic values for the activities of CYP19A1 and its polymorphic variants supported by variant forms of POR. For the conversion of androstenedione to estrone, variable amounts $(0.3-30 \mu \mathrm{M})$ of androstenedione were used for enzyme assays, and the NADPH was fixed at $1 \mathrm{mM}$. Data are shown as mean \pm SEM of three independent replicates. Catalytic efficiencies of different combinations of POR and CYP19A1 variants are given as a percentage of WT-POR and WT-CYP19A1 combination (\% of WTWT catalytic efficiency). * represents statistically significant differences from the POR-WT control (*p<0.05 based on two tailed students t-test).

\begin{tabular}{|c|c|c|c|c|}
\hline & $\begin{array}{c}\text { Km, Androstenedione } \\
(\mu \mathrm{M})\end{array}$ & $\begin{array}{c}\text { Vmax } \\
\mathrm{pmol} / \mathrm{min} / \mathrm{nmol}\end{array}$ & Vmax/Km & $\begin{array}{c}\text { \% of WT- } \\
\text { WT } \\
\text { catalytic } \\
\text { efficiency }\end{array}$ \\
\hline \multicolumn{5}{|l|}{ POR-P284L } \\
\hline CYP19A1-WT & $99.7 \pm 312.0$ & $37.4 \pm 92.7$ & 0.4 & 1.7 \\
\hline CYP19A1-R264H & $55.2 \pm 49.7$ & $38.6 \pm 24.0$ & 0.7 & 3.2 \\
\hline CYP19A1-R264C & n.d. & n.d. & n.d. & n.d. \\
\hline \multicolumn{5}{|l|}{ POR-P284T } \\
\hline CYP19A1-WT & $22.5 \pm 36.2$ & $15.8 \pm 13.2$ & 0.7 & 3.3 \\
\hline CYP19A1-R264H & $51.0 \pm 56.5$ & $24.5 \pm 18.7$ & 0.5 & 2.2 \\
\hline CYP19A1-R264C & $19.9 \pm 31.7$ & $28.7 \pm 22.0$ & 1.4 & 6.7 \\
\hline \multicolumn{5}{|l|}{ POR-Y607C } \\
\hline CYP19A1-WT & $4.7 \pm 2.5$ & $18.3 \pm 3.0^{*}$ & $3.9^{*}$ & $18.2^{*}$ \\
\hline CYP19A1-R264H & $1.3 \pm 0.6$ & $17.7 \pm 1.7^{*}$ & 13.6 & 63.1 \\
\hline CYP19A1-R264C & $77.5 \pm 133.6$ & $81.1 \pm 105.0$ & 1.0 & 4.8 \\
\hline
\end{tabular}

\section{Stability analysis of CYP19A1 and its} polymorphic variants $\mathrm{R} 264 \mathrm{H}$ and $\mathrm{R} 264 \mathrm{C}$ by Fast Proteolysis Assay (FASTpp)

To compare the biophysical protein stability of CYP19A1 and its polymorphic variants R264H and R264C, we used a FASTpp assay with the recombinantly expressed and purified CYP19A1 proteins. CYP19A1-WT and variants were exposed in parallel to a range of different temperatures with the thermostable protease Thermolysin. Thermolysin readily cleaves the unfolded proteins near the hydrophobic residues Phe, Leu, Ile, and Val $(42,43)$ but does not cleave the folded parts of the 
protein. Increasing the reaction temperature induces the thermal unfolding of proteins and the temperature-dependent changes in the degradation pattern represent the readout for the thermal stability of proteins. The SDS-PAGE analysis of the parallel FASTpp of CYP19A1-WT and variants (Figure 4A and B) showed that the $\mathrm{R} 264 \mathrm{H}$ and R264C mutations do not display any major changes in protein stability. Therefore, it seems likely that the conformational changes induced by $\mathrm{R} 264 \mathrm{C}$ and $\mathrm{R} 264 \mathrm{H}$ variations do not significantly alter the structural stability of CYP19A1. However, the structural changes caused by R264C and R264H variations may alter the delicate balance of proteinprotein interactions that are needed for the transfer of electrons from POR to CYP19A1.

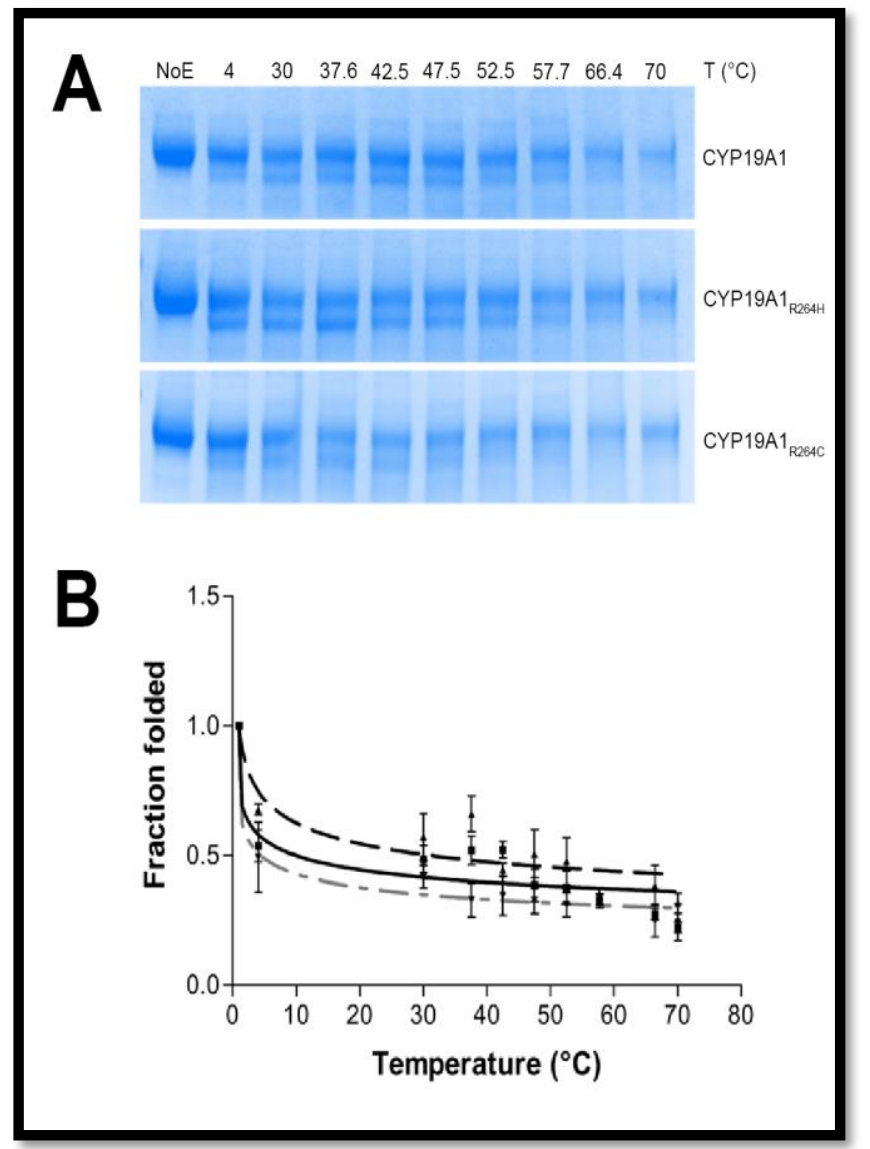

Figure 4: FastPP assay for the stability of CYP19A1 variants. Protein stability analysis of aromatase mutants CYP19A1 $1_{\mathrm{R} 264 \mathrm{H}}$ (dashed line) and CYP19A1 $1_{\mathrm{R} 264 \mathrm{C}}$ (dasheddotted line) compared to CYP19A1-WT (solid line) by FASTpp assay. Thermolysin (0.05) $\mathrm{mg} / \mathrm{mL}$ ) was used to digest $0.20 \mathrm{mg} / \mathrm{mL}$ of CYP19A1-WT or mutants at increasing temperatures ranging from $4^{\circ} \mathrm{C}$ to $70^{\circ} \mathrm{C}$. NoE represents the negative control carried out without thermolysin. The experiments were repeated three times, and here, a representative SDS-PAGE is shown. Each data-set represents mean \pm SEM of three experiments. Data were analysed by Dunnett's multiple comparisons test and the differences were not found to be statistically significant between the groups, indicating all variants have similar stability as the WTCYP19A1.

Variable effects on the enzyme activity of CYP19A1 and its polymorphic variants $R 264 H$ and $\mathrm{R} 264 \mathrm{C}$ are shown by $\mathrm{POR}$ variants

To study how different variants of CYP19A1 interact with variants of POR, we tested three polymorphic variants of POR (P284L, P284T, and Y607C) in supporting CYP19A1 enzyme activity. We tested the in-vitro estrogen synthase activity of CYP19A1 by the tritiated water release assay with the reconstituted liposomes using androstenedione as a substrate. The POR variants P284L and P284T showed a severe loss of enzyme activity with all CYP19A1 variants tested (Figure 5A-B, Table 4). For the POR variant P284L, the Km (apparent) for androstenedione was elevated $\sim 60$ fold and $\sim 35$ fold as compared to WT POR with CYP19A1 and CYP19A1-R264H. The apparent Vmax of PORP284L was comparable to that of POR-WT in supporting CYP19A1 and CYP19A1-R264H activity. However, the product of enzymatic reaction with POR-P284L and CYP19A1-R264C was undetectable, and therefore, $\mathrm{Km}$ and Vmax could not be determined. For the POR-P284T, the $\mathrm{Km}$ (apparent) for androstenedione was elevated by $\sim 14, \sim 32$, and $\sim 12$ fold with the CYP19A1-WT, CYP19A1-R264H, and CYP19A1-R264C respectively. The apparent $\mathrm{Vmax}$ was reduced by $\sim 55 \%, \sim 30 \%$, and $\sim 20 \%$ with the CYP19A1-WT, CYP19A1-R264H, and CYP19A1-R264C, respectively.

\section{POR-Y607C variant supports CYP19A1-R264H better than WT CYP19A1.}

For the POR variant Y607C, the Km (apparent) for androstenedione was elevated by $\sim 3$ and $\sim 48$ fold with the CYP19A1-WT and CYP19A1-R264C respectively (Figure 5C, Table 4). The apparent Vmax was reduced by $\sim 50 \%$, with both CYP19A1WT and CYP19A1-R264H. The residual catalytic efficiency of CYP19A1-WT, CYP19A1-R264H, and CYP19A1-R264C with POR-Y607C was 
$18.2 \%, 63.1$ and $4.8 \%$ respectively as compared to POR-WT: CYP19A1-WT activity. Interestingly, the POR-Y607C variant supports the reaction of CYP19A1-R264H better than CYP19A1-WT.

\section{Discussion}

POR is the obligate electron donor for all P450 enzymes in the endoplasmic reticulum and supplies electrons for the catalytic activities of CYP19A1 $[42,68,84]$. The CYP19A1 deficiency is linked to genetic disorders of estrogen biosynthesis in women and developmental disorders in men [19, 31, 46, 85, 86]. Previously we have tested the CYP19A1 variants (R264C and R26H) and POR genetic variants in separate studies that focused on individual genes [59, 64, 70]. Cytochromes P450 and $\mathrm{P} 450$ reductase have a large number of genetic variations and, therefore, many individuals may harbor variations in P450 reductase as well as P450 genes that may alter the enzymatic activities of cytochromes P450 [87]. So far, combined effects of variations in $\mathrm{P} 450$ reductase and steroidogenic $\mathrm{P} 450$ have not been tested, despite many reports on effects of genetic variations that were tested separately, using the WT P450 proteins with variant forms of POR; or P450 variants tested with WT-POR. There is only one report in literature describing the effects of genetic variations in a $\mathrm{P} 450$ protein (CYP2C9) with some POR variations [63].

In this report, we have tested the combinations of genetic variants in CYP19A1, responsible for estrogen production, with variant forms of POR. The R264C is a common polymorphism in CYP19A1 with a higher frequency in Asian and African populations compared to American, Mexican, or European populations. The only exception was found in the Maasai population from Kinyawa in Kenya, where the R264C variant of the CYP19A1 was present at a frequency similar to that of European or American populations (Table 1). The prevalence of the $\mathrm{R} 264 \mathrm{C}$ variant of the CYP19A1 is high in Japanese, Chines, and southeast Asian populations. Among the POR variants studied, The Y607C has also been observed in the southeast Asian population [59]. In the CYP19A1 activity assays using bacterially expressed recombinant forms of POR and CYP19A1 proteins, we studied the combined effects of POR and CYP19A1 variants in different permutations and combinations of the two proteins. First, we tested the variant forms of CYP19A1 with WT POR and found that the CYP19A1-R264C variant lost around $85 \%$ of CYP19A1 catalytic efficiency, while the catalytic efficiency of CYP19A1-R264H variant was decreased by $14 \%$ when compared to WTCYP19A1. These data are similar to the previous reports, where the two CYP19A1 polymorphic variants showed a decrease in the catalytic efficiency compared to the WT protein [51]. However, in this work, the amount of the activity loss was different, and this can be explained with a different experimental setup due to the incorporation of the enzymes in liposomes, the use of higher amounts of POR (4:1 versus 1:1 ratio) and the different assay of CYP19A1 activity used in the study.

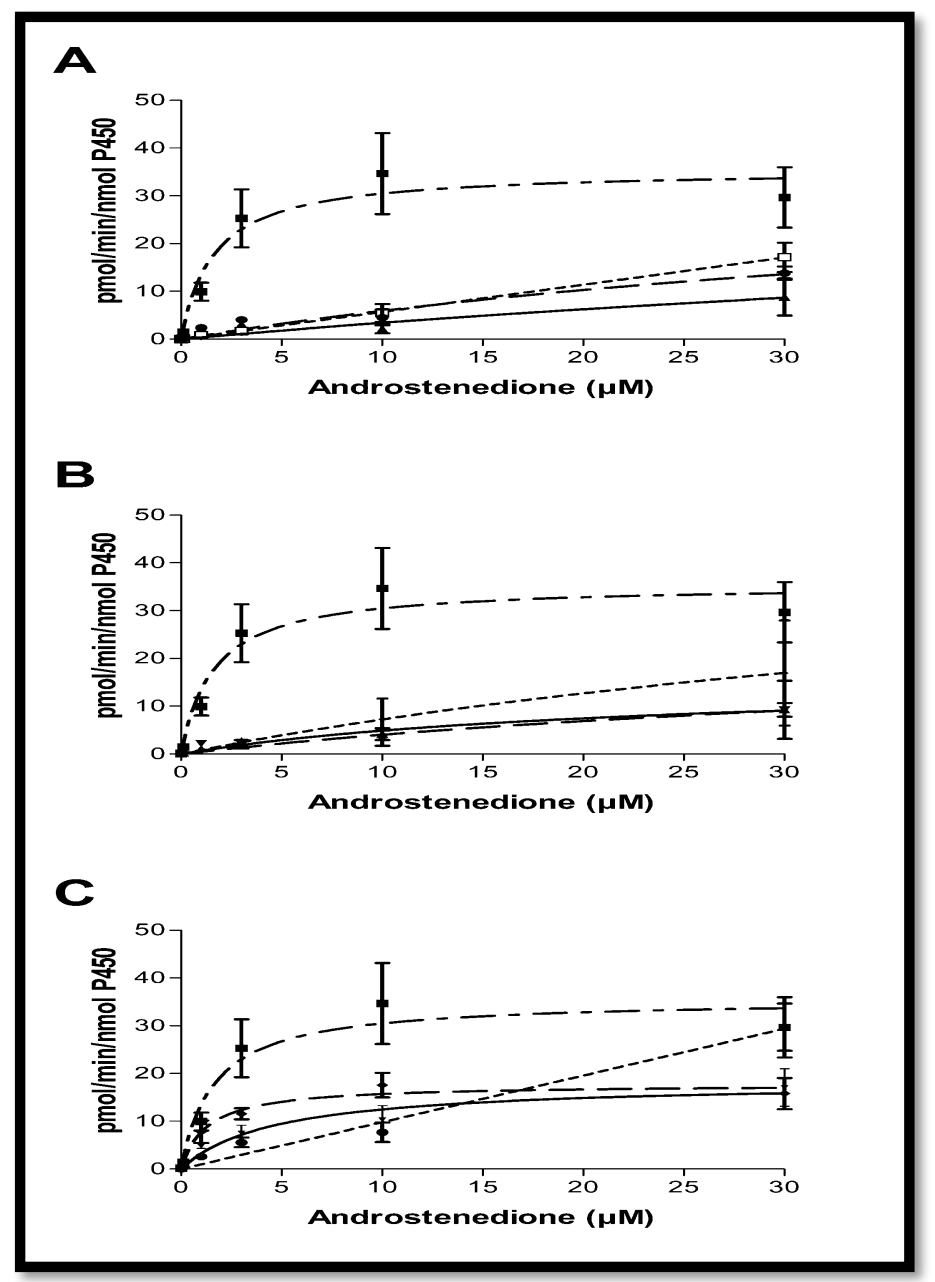

Figure 5: Enzyme assay of CYP19A1 variants . WTCYP19A1(solid line), R264H-CYP19A1 (dashed line) and R264C-CYP19A1 (dotted line) activities supported by A: 
POR-P284L, B: POR-P284T, C: POR-Y607C. CYP19A1 activity supported by the wild type POR is shown in all three graphs as a reference (dash-dotted line). Human CYP19A1 (WT and variants R264C/R264H) and human POR (WT and variants $\mathrm{P} 284 \mathrm{~L} / \mathrm{P} 284 \mathrm{~T} / \mathrm{Y} 607 \mathrm{C})$ were embedded into liposomes, and aromatization activity to convert androstenedione into estrone was monitored by the release of ${ }^{3} \mathrm{H}$ water during the reaction. Data are shown as mean $\pm \mathrm{SEM}$ of three independent replicates. Data were fitted with GraphPad Prism using the kinetics model described by Michaelis and Menten. The $\mathrm{K}_{\mathrm{m}}$ and $\mathrm{V}_{\max }$ values calculated from these experiments and statistical analysis are shown in Table 3 and Table 4.

POR is a membrane-bound protein that uses NADPH as a substrate for electron transfer. The binding of NADPH results in a conformational change that brings NAHPH close to the bound FAD in POR for the transfer of electrons. Afterward, additional changes in conformation cause a tightening of the POR structure, which brings the FAD closer to the FMN for the transfer of electrons from FAD to FMN. The P450 redox partners of POR interact with the FMN binding domain through ionic interactions involving lysine and arginine residues on the surface of $\mathrm{P} 450$ s and the glutamate and aspartate residues located on the surface of POR [88-91]. Considering the importance of the hinge region of POR in both the intermolecular electron transfer as well as interactions with partner proteins, we studied the effects of variations in the hinge region of $\mathrm{POR}$ on the enzymatic activities of CYP19A1 variants. The main reason behind such sensitivity of CYP19A1 towards changes in POR may be due to its requirement of six pairs of electrons to complete the conversion of androgens (androstenedione, testosterone) to estrogens (estrone, estradiol). By this logic, it is possible that changes in the conformation of POR that affect interactions with CYP19A1, could, in turn, affect CYP19A1 activities. The P284L (rs 72557938) and P284T (rs72557937) variants are situated in the flexible hinge region of POR, which is important for movements of different domains, including the interactions between FMN and FAD-binding domains for the transfer of electrons from FAD to FMN (Figure 2B). In a study by Miller laboratory which analyzed genetic variations of POR in different populations, the POR variant $\mathrm{P} 284 \mathrm{~L}$ was found with an allele frequency of 0.003 in the Chinese Americans [76], and in the ExAc dataset from NCBI, the P284L variant of POR has an allele frequency of 0.00004 . Huang et al. have reported a $54 \%$ loss of CYP17A1 17 $\alpha$-hydroxylase activity with POR P284L but found the 17,20 lyase activity of CYP17A1 to be similar to the wild type POR [76]. Recently we have shown that the P284L and P284T variants of POR showed reduced enzymatic activities with several drug-metabolizing cytochromes P450 [83, 87]. There was a 55\% loss of activity in CYP2C19 and CYP3A5 assays, while a $78 \%$ loss of activity was observed in CYP2C9 assays with the P284L variant of POR compared to the WT protein [87]. Flavin content was not affected by the variation P284L in POR [64], indicating a change in protein-protein interactions, both the inter as well as intramolecular; may be behind the reduced CYP19A1 activities. In case of P284T variant of POR a reduction of both the FAD as well as FMN content has been observed [83]. The drug metabolizing cytochrome P450 enzyme activities were also reduced when the POR-P284T was used as a redox partner (CYP2C9, 26\%; CYP2C19, 44\%; CYP3A4, 23\% and CYP3A5, 44\% of WT POR) [83]. Because the flexible hinge region of POR is necessary for the movement of domains that brings the FAD closer to the FMN for the transfer of electrons, a change in the hinge region may alter the electron transfer process in POR, affecting the activities of redox partners [92]. It is likely that some electron transfer partners of POR may show a more significant effects on their enzymatic activities, while other redox partners of POR might remain unaffected depending on the precise nature of their interactions with the POR [93].

As seen with the P284L, P284T, and the Y607C mutations, there may be variations of POR in the seemingly non-clinical populations that show adverse effects on the enzymatic activities of multiple cytochrome P450 enzymes. Since variations in POR are now linked to the changes in the metabolism of many drugs, steroids, and small molecule substrates, variations in the POR gene should be considered as a candidate for genetic defects causing abnormal steroid or drug metabolism [59, 60, 62, 64, 75]. Further studies on genetic variants of POR shall be conducted to check the potentially harmful effect of individual POR variants. 
Acknowledgments

This work was supported by grants to AVP from the Novartis Foundation for Medical-Biological Research (18A053), the Swiss National Science Foundation (31003A-134926), and Burgergemiende Bern and by a CRT Foundation grant (project "Exposome" RF = 2016.2780) to GDN.

\section{References}

[1] E.R. Simpson, M.S. Mahendroo, G.D. Means, M.W. Kilgore, M.M. Hinshelwood, S. Graham-Lorence, B. Amarneh, Y. Ito, C.R. Fisher, M.D. Michael, et al., Aromatase cytochrome P450, the enzyme responsible for estrogen biosynthesis, Endocr Rev 15(3) (1994) 342-355.

[2] M. Shozu, K. Akasofu, T. Harada, Y. Kubota, A new cause of female pseudohermaphroditism: placental aromatase deficiency, J Clin Endocrinol Metab 72(3) (1991) 560-566.

[3] N. Harada, H. Ogawa, M. Shozu, K. Yamada, K. Suhara, E. Nishida, Y. Takagi, Biochemical and molecular genetic analyses on placental aromatase (P-450AROM) deficiency, J Biol Chem 267(7) (1992) 4781-4785.

[4] U.M. Zanger, M. Schwab, Cytochrome P450 enzymes in drug metabolism: regulation of gene expression, enzyme activities, and impact of genetic variation, Pharmacol Ther 138(1) (2013) 103-141.

[5] F. Hannemann, A. Bichet, K.M. Ewen, R. Bernhardt, Cytochrome P450 systems--biological variations of electron transport chains, Biochim Biophys Acta 1770(3) (2007) 330-344. [6] A. Zalewski, N.S. Ma, B. Legeza, N. Renthal, C.E. Flück, A.V. Pandey, Vitamin D-Dependent Rickets Type 1 Caused by Mutations in CYP27B1 Affecting Protein Interactions With Adrenodoxin, J Clin Endocrinol Metab 101(9) (2016) 3409-3418.

[7] T. Omura, Mitochondrial P450s, Chem Biol Interact 163(1-2) (2006) 86-93.

[8] P. Rodriguez Castano, S. Parween, A.V. Pandey, Bioactivity of Curcumin on the Cytochrome P450 Enzymes of the Steroidogenic Pathway, Int J Mol Sci 20(18) (2019).

[9] J. Malikova, T. Zingg, R. Fingerhut, S. Sluka, M. Grossl, S. Brixius-Anderko, R. Bernhardt, J. McDougall, A.V. Pandey, C.E. Fluck, HIV Drug Efavirenz Inhibits CYP21A2 Activity with Possible Clinical Implications, Hormone research in paediatrics 91(4) (2019) 262-270.

[10] J. Malikova, S. Brixius-Anderko, S.S. Udhane, S. Parween, B. Dick, R. Bernhardt, A.V. Pandey, CYP17A1 inhibitor abiraterone, an anti-prostate cancer drug, also inhibits the 21-hydroxylase activity of CYP21A2, J Steroid Biochem Mol Biol 174 (2017) 192-200.

[11] S.S. Udhane, B. Dick, Q. Hu, R.W. Hartmann, A.V. Pandey, Specificity of anti-prostate cancer CYP17A1 inhibitors on androgen biosynthesis, Biochem Biophys Res Commun 477(4) (2016) 1005-1010.
[12] T. Omura, Contribution of cytochrome P450 to the diversification of eukaryotic organisms, Biotechnol Appl Biochem 60(1) (2013) 4-8.

[13] B.C. Chung, K.J. Matteson, W.L. Miller, Structure of a bovine gene for P-450c21 (steroid 21-hydroxylase) defines a novel cytochrome P-450 gene family, Proc Natl Acad Sci U S A 83(12) (1986) 4243-4247.

[14] B.C. Chung, K.J. Matteson, R. Voutilainen, T.K. Mohandas, W.L. Miller, Human cholesterol side-chain cleavage enzyme, P450scc: cDNA cloning, assignment of the gene to chromosome 15, and expression in the placenta, Proc Natl Acad Sci U S A 83(23) (1986) 8962-8966.

[15] K.J. Matteson, B.C. Chung, M.S. Urdea, W.L. Miller, Study of cholesterol side-chain cleavage (20,22 desmolase) deficiency causing congenital lipoid adrenal hyperplasia using bovine-sequence P450scc oligodeoxyribonucleotide probes, Endocrinology 118(4) (1986) 1296-1305.

[16] B.C. Chung, J. Picado-Leonard, M. Haniu, M. Bienkowski, P.F. Hall, J.E. Shively, W.L. Miller, Cytochrome P450c17 (steroid 17 alpha-hydroxylase/17,20 lyase): cloning of human adrenal and testis cDNAs indicates the same gene is expressed in both tissues, Proc Natl Acad Sci U S A 84(2) (1987) 407-411.

[17] Y. Morel, J. Picado-Leonard, D.A. Wu, C.Y. Chang, T.K. Mohandas, B.C. Chung, W.L. Miller, Assignment of the functional gene for human adrenodoxin to chromosome 11q13---qter and of adrenodoxin pseudogenes to chromosome 20cen---q13.1, Am J Hum Genet 43(1) (1988) 52-59.

[18] M. Fernandez-Cancio, N. Camats, C.E. Fluck, A. Zalewski, B. Dick, B.M. Frey, R. Monne, N. Toran, L. Audi, A.V. Pandey, Mechanism of the Dual Activities of Human CYP17A1 and Binding to Anti-Prostate Cancer Drug Abiraterone Revealed by a Novel V366M Mutation Causing 17,20 Lyase Deficiency, Pharmaceuticals 11(2) (2018).

[19] C.M. Pepe, N.I. Saraco, M.S. Baquedano, G. Guercio, E. Vaiani, R. Marino, A.V. Pandey, C.E. Fluck, M.A. Rivarola, A. Belgorosky, The cytochrome P450 aromatase lacking exon 5 is associated with a phenotype of nonclassic aromatase deficiency and is also present in normal human steroidogenic tissues, Clin Endocrinol (Oxf) 67(5) (2007) 698-705.

[20] M. Janner, A.V. Pandey, P.E. Mullis, C.E. Flück, Clinical and biochemical description of a novel CYP21A2 gene mutation 962_963insA using a new 3D model for the P450c21 protein, Eur J Endocrinol 155(1) (2006) 143-151.

[21] W.L. Miller, N. Huang, C.E. Flück, A.V. Pandey, P450 oxidoreductase deficiency, Lancet 364(9446) (2004) 1663.

[22] W.L. Miller, B.C. Chung, The First Defect in Electron Transfer to Mitochondrial P450 Enzymes, Endocrinology 157(3) (2016) 1003-1006.

[23] W.L. Miller, Minireview: regulation of steroidogenesis by electron transfer, Endocrinology 146(6) (2005) 2544-2550.

[24] C.E. Flück, T. Tajima, A.V. Pandey, W. Arlt, K. Okuhara, C.F. Verge, E.W. Jabs, B.B. Mendonca, K. Fujieda, W.L. Miller, Mutant P450 oxidoreductase causes disordered 
steroidogenesis with and without Antley-Bixler syndrome, Nat Genet 36(3) (2004) 228-230.

[25] H.H. Nguyen, F. Hannemann, M.F. Hartmann, E.M. Malunowicz, S.A. Wudy, R. Bernhardt, Five novel mutations in CYP11B2 gene detected in patients with aldosterone synthase deficiency type I: Functional characterization and structural analyses, Mol Genet Metab 100(4) (2010) 357-364.

[26] S.E. Bulun, E.R. Simpson, Regulation of aromatase expression in human tissues, Breast cancer research and treatment 30(1) (1994) 19-29.

[27] J.P. Bilezikian, A. Morishima, J. Bell, M.M. Grumbach, Increased bone mass as a result of estrogen therapy in a man with aromatase deficiency, N Engl J Med 339(9) (1998) 599-603. [28] V. Rochira, A. Balestrieri, M. Faustini-Fustini, S. Borgato, P. Beck-Peccoz, C. Carani, Pituitary function in a man with congenital aromatase deficiency: effect of different doses of transdermal E2 on basal and stimulated pituitary hormones, J Clin Endocrinol Metab 87 (2002) 2857-2862.

[29] L. Lin, O. Ercan, J. Raza, C.P. Burren, S.M. Creighton, R.J. Auchus, M.T. Dattani, J.C. Achermann, Variable phenotypes associated with aromatase (CYP19) insufficiency in humans, J Clin Endocrinol Metab 92(3) (2007) 982-990.

[30] A. Belgorosky, G. Guercio, C. Pepe, N. Saraco, M.A. Rivarola, Genetic and clinical spectrum of aromatase deficiency in infancy, childhood and adolescence, Horm Res 72(6) (2009) 321-330.

[31] F.A. Conte, M.M. Grumbach, Y. Ito, C.R. Fisher, E.R. Simpson, A syndrome of female pseudohermaphrodism, hypergonadotropic hypogonadism, and multicystic ovaries associated with missense mutations in the gene encoding aromatase (P450arom), J Clin Endocrinol Metab 78(6) (1994) 1287-1292.

[32] E.R. Simpson, Aromatase: biologic relevance of tissuespecific expression, Semin Reprod Med 22(1) (2004) 11-23.

[33] S. Nakajin, M. Shinoda, P.F. Hall, Purification to homogeneity of aromatase from human placenta, Biochem. Biophys. Res. Commun. 134 (1986) 704-710.

[34] J.T. Kellis, L.E. Vickery, Purification and characterization of human placental aromatase cytochrome P450, J. Biol. Chem. 262 (1987) 4413-4420.

[35] N. Harada, Novel properties of human placental aromatase as cytochrome P-450: Purification and characterization of a unique form of aromatase., J Biochem (Tokyo) 103(1) (1988) 106-133.

[36] D. Ghosh, J. Griswold, M. Erman, W. Pangborn, Structural basis for androgen specificity and oestrogen synthesis in human aromatase, Nature 457(7226) (2009) 219223.

[37] M.M. Grumbach, R.J. Auchus, Estrogen: consequences and implications of human mutations in synthesis and action, J Clin Endocrinol Metab 84(12) (1999) 4677-4694.

[38] C. Stocco, Tissue physiology and pathology of aromatase, Steroids 77(1-2) (2012) 27-35.
[39] G. Di Nardo, G. Gilardi, Human aromatase: perspectives in biochemistry and biotechnology, Biotechnol Appl Biochem 60(1) (2013) 92-101.

[40] J. Neunzig, M. Milhim, L. Schiffer, Y. Khatri, J. Zapp, A. Sanchez-Guijo, M.F. Hartmann, S.A. Wudy, R. Bernhardt, The steroid metabolite 16(beta)-OH-androstenedione generated by CYP21A2 serves as a substrate for CYP19A1, J Steroid Biochem Mol Biol 167 (2017) 182-191.

[41] M.B. Murataliev, R. Feyereisen, A. Walker, Electron transfer by diflavin reductases, Bba-Proteins Proteom 1698(1) (2004) 1-26.

[42] A.V. Pandey, C.E. Flück, NADPH P450 oxidoreductase: structure, function, and pathology of diseases, Pharmacol Ther 138(2) (2013) 229-254.

[43] P.J. Mak, A. Luthra, S.G. Sligar, J.R. Kincaid, Resonance Raman spectroscopy of the oxygenated intermediates of human CYP19A1 implicates a compound i intermediate in the final lyase step, J Am Chem Soc 136(13) (2014) 4825-4828.

[44] Y. Khatri, A. Luthra, R. Duggal, S.G. Sligar, Kinetic solvent isotope effect in steady-state turnover by CYP19A1 suggests involvement of Compound 1 for both hydroxylation and aromatization steps, FEBS Lett 588(17) (2014) 3117-3122.

[45] M. Akhtar, J.N. Wright, Acyl-Carbon Bond Cleaving Cytochrome P450 Enzymes: CYP17A1, CYP19A1 and CYP51A1, Adv Exp Med Biol 851 (2015) 107-130.

[46] N. Bouchoucha, D. Samara-Boustani, A.V. Pandey, H. Bony-Trifunovic, G. Hofer, Y. Aigrain, M. Polak, C.E. Flück, Characterization of a novel CYP19A1 (aromatase) R192H mutation causing virilization of a $46, \mathrm{XX}$ newborn, undervirilization of the $46, \mathrm{XY}$ brother, but no virilization of the mother during pregnancies, Mol Cell Endocrinol 390(1-2) (2014) 8-17.

[47] A. Morishima, M.M. Grumbach, E.R. Simpson, C. Fisher, K. Qin, Aromatase deficiency in male and female siblings caused by a novel mutation and the physiological role of estrogens, J Clin Endocrinol Metab 80(12) (1995) 3689-3698.

[48] I. Czajka-Oraniec, E.R. Simpson, Aromatase research and its clinical significance, Endokrynol Pol 61(1) (2010) 126134.

[49] P.E. Mullis, N. Yoshimura, B. Kuhlmann, K. Lippuner, P. Jaeger, H. Harada, Aromatase deficiency in a female who is compound heterozygote for two new point mutations in the P450arom gene: impact of estrogens on hypergonadotropic hypogonadism, multicystic ovaries, and bone densitometry in childhood, J Clin Endocrinol Metab 82(6) (1997) 1739-1745.

[50] M. Ludwig, A. Beck, L. Wickert, U. Bolkenius, B. Tittel, K. Hinkel, F. Bidlingmaier, Female pseudohermaphroditism associated with a novel homozygous G-to-A (V370-to-M) substitution in the P-450 aromatase gene, J Pediatr Endocrinol Metab 11(5) (1998) 657-664.

[51] J. Deladoey, C. Fluck, M. Bex, N. Yoshimura, N. Harada, P.E. Mullis, Aromatase deficiency caused by a novel P450arom gene mutation: impact of absent estrogen production on serum gonadotropin concentration in a boy, J Clin Endocrinol Metab 84(11) (1999) 4050-4054. 
[52] L. Maffei, Y. Murata, V. Rochira, G. Tubert, C. Aranda, M. Vazquez, C.D. Clyne, S. Davis, E.R. Simpson, C. Carani, Dysmetabolic syndrome in a man with a novel mutation of the aromatase gene: effects of testosterone, alendronate, and estradiol treatment, J Clin Endocrinol Metab 89(1) (2004) 61-70. [53] M. Shozu, S. Sebastian, K. Takayama, W.T. Hsu, R.A. Schultz, K. Neely, M. Bryant, S.E. Bulun, Estrogen excess associated with novel gain-of-function mutations affecting the aromatase gene, N Engl J Med 348(19) (2003) 1855-1865.

[54] C.A. Stratakis, A. Vottero, A. Brodie, L.S. Kirschner, D. DeAtkine, Q. Lu, W. Yue, C.S. Mitsiades, A.W. Flor, G.P. Chrousos, The aromatase excess syndrome is associated with feminization of both sexes and autosomal dominant transmission of aberrant P450 aromatase gene transcription, J Clin Endocrinol Metab 83(4) (1998) 1348-1357.

[55] R. Baravalle, F. Valetti, G. Catucci, G. Gambarotta, M. Chiesa, S. Maurelli, E. Giamello, I. Barone, S. Catalano, S. Ando, G. Di Nardo, G. Gilardi, Effect of sildenafil on human aromatase activity: From in vitro structural analysis to catalysis and inhibition in cells, J Steroid Biochem Mol Biol 165(Pt B) (2017) 438-447.

[56] R. Baravalle, A. Ciaramella, F. Baj, G. Di Nardo, G. Gilardi, Identification of endocrine disrupting chemicals acting on human aromatase, Biochimica et biophysica acta. Proteins and proteomics 1866(1) (2018) 88-96.

[57] G. Di Nardo, G. Cimicata, R. Baravalle, V. Dell'Angelo, A. Ciaramella, G. Catucci, P. Ugliengo, G. Gilardi, Working at the membrane interface: Ligand-induced changes in dynamic conformation and oligomeric structure in human aromatase, Biotechnol Appl Biochem 65(1) (2018) 46-53.

[58] M. Adachi, K. Tachibana, Y. Asakura, T. Yamamoto, K. Hanaki, A. Oka, Compound heterozygous mutations of cytochrome P450 oxidoreductase gene (POR) in two patients with Antley-Bixler syndrome, Am J Med Genet A 128A(4) (2004) 333-339.

[59] F.Z. Burkhard, S. Parween, S.S. Udhane, C.E. Flück, A.V. Pandey, P450 Oxidoreductase deficiency: Analysis of mutations and polymorphisms, J Steroid Biochem Mol Biol 165 (2017) 38-50.

[60] A.V. Pandey, P. Sproll, Pharmacogenomics of human P450 oxidoreductase, Front Pharmacol 5 (2014) 103.

[61] C.E. Flück, A.V. Pandey, Steroidogenesis of the testis -- new genes and pathways, Ann Endocrinol (Paris) 75(2) (2014) $40-47$.

[62] C.E. Flück, A.V. Pandey, Human P450 Oxidoreductase Deficiency, in: I. Huhtaniemi, L. Martini (Eds.), Encyclopedia of Endocrine Diseases (Second Edition), Academic Press, Oxford, 2019. pp. 431-443.

[63] M. Subramanian, V. Agrawal, D. Sandee, H.K. Tam, W.L. Miller, T.S. Tracy, Effect of P450 oxidoreductase variants on the metabolism of model substrates mediated by CYP2C9.1, CYP2C9.2, and CYP2C9.3, Pharmacogenet Genomics 22(8) (2012) 590-597.

[64] S.S. Udhane, S. Parween, N. Kagawa, A.V. Pandey, Altered CYP19A1 and CYP3A4 Activities Due to Mutations
A115V, T142A, Q153R and P284L in the Human P450 Oxidoreductase, Front Pharmacol 8 (2017) 580.

[65] C.E. Flück, A.V. Pandey, Impact on CYP19A1 activity by mutations in NADPH cytochrome P450 oxidoreductase, J Steroid Biochem Mol Biol 165(Pt A) (2017) 64-70.

[66] S. Parween, F. Roucher-Boulez, C.E. Flück, A. Lienhardt-Roussie, D. Mallet, Y. Morel, A.V. Pandey, P450 Oxidoreductase Deficiency: Loss of Activity Caused by Protein Instability From a Novel L374H Mutation, J Clin Endocrinol Metab 101(12) (2016) 4789-4798.

[67] C.E. Flück, D. Mallet, G. Hofer, D. Samara-Boustani, J. Leger, M. Polak, Y. Morel, A.V. Pandey, Deletion of P399_E401 in NADPH cytochrome P450 oxidoreductase results in partial mixed oxidase deficiency, Biochem Biophys Res Commun 412(4) (2011) 572-577.

[68] A.V. Pandey, P. Kempna, G. Hofer, P.E. Mullis, C.E. Flück, Modulation of human CYP19A1 activity by mutant NADPH P450 oxidoreductase, Mol Endocrinol 21(10) (2007) 2579-2595.

[69] J. Lo, G. Di Nardo, J. Griswold, C. Egbuta, W. Jiang, G. Gilardi, D. Ghosh, Structural basis for the functional roles of critical residues in human cytochrome p450 aromatase, Biochemistry 52(34) (2013) 5821-5829.

[70] R. Baravalle, G. Di Nardo, A. Bandino, I. Barone, S. Catalano, S. Ando, G. Gilardi, Impact of R264C and R264H polymorphisms in human aromatase function, J Steroid Biochem Mol Biol 167 (2017) 23-32.

[71] N. Kagawa, Efficient expression of human aromatase (CYP19) in E. coli, Methods Mol Biol 705 (2011) 109-122.

[72] N. Kagawa, H. Hori, M.R. Waterman, S. Yoshioka, Characterization of stable human aromatase expressed in $\mathrm{E}$. coli, Steroids 69(4) (2004) 235-243.

[73] N. Kagawa, Q. Cao, K. Kusano, Expression of human aromatase (CYP19) in Escherichia coli by N-terminal replacement and induction of cold stress response, Steroids 68(2) (2003) 205-209.

[74] N. Huang, A.V. Pandey, V. Agrawal, W. Reardon, P.D. Lapunzina, D. Mowat, E.W. Jabs, G. Van Vliet, J. Sack, C.E. Flück, W.L. Miller, Diversity and function of mutations in p450 oxidoreductase in patients with Antley-Bixler syndrome and disordered steroidogenesis, Am J Hum Genet 76(5) (2005) 729749 .

[75] C. Nicolo, C.E. Flück, P.E. Mullis, A.V. Pandey, Restoration of mutant cytochrome $\mathrm{P} 450$ reductase activity by external flavin, Mol Cell Endocrinol 321(2) (2010) 245-252.

[76] N. Huang, V. Agrawal, K.M. Giacomini, W.L. Miller, Genetics of P450 oxidoreductase: sequence variation in 842 individuals of four ethnicities and activities of 15 missense mutations, Proc Natl Acad Sci U S A 105(5) (2008) 1733-1738.

[77] A.V. Pandey, C.E. Flück, P.E. Mullis, Altered heme catabolism by heme oxygenase-1 caused by mutations in human NADPH cytochrome P450 reductase, Biochem Biophys Res Commun 400(3) (2010) 374-378.

[78] E.D. Lephart, E.R. Simpson, Assay of aromatase activity, Methods Enzymol 206 (1991) 477-483. 
[79] M.C. Miletta, A. Eble, M. Janner, S. Parween, A.V. Pandey, C.E. Fluck, P.E. Mullis, IGHD II: A Novel GH-1 Gene Mutation (GH-L76P) Severely Affects GH Folding, Stability, and Secretion, J Clin Endocrinol Metab 100(12) (2015) E15751583.

[80] D.P. Minde, M.M. Maurice, S.G. Rudiger, Determining biophysical protein stability in lysates by a fast proteolysis assay, FASTpp, PLoS One 7(10) (2012) e46147.

[81] T.D. Porter, C.B. Kasper, NADPH-cytochrome P-450 oxidoreductase: flavin mononucleotide and flavin adenine dinucleotide domains evolved from different flavoproteins, Biochemistry 25(7) (1986) 1682-1687.

[82] N. Huang, V. Agrawal, K.M. Giacomini, W.L. Miller, Genetics of P450 oxidoreductase: Sequence variation in 842 individuals of four ethnicities and activities of 15 missense mutations, Proceedings of the National Academy of Sciences of the United States of America 105(5) (2008) 1733-1738.

[83] S. Parween, M.N. Rojas Velazquez, S.S. Udhane, N. Kagawa, A.V. Pandey, Variability in Loss of Multiple Enzyme Activities Due to the Human Genetic Variation P284T Located in the Flexible Hinge Region of NADPH Cytochrome P450 Oxidoreductase, Frontiers in Pharmacology 10(1187) (2019).

[84] B.S. Masters, R.T. Okita, The history, properties, and function of NADPH-cytochrome P-450 reductase, Pharmacol Ther 9(2) (1980) 227-244.

[85] C. Carani, K. Qin, M. Simoni, M. Faustini-Fustini, S. Serpente, J. Boyd, K.S. Korach, E.R. Simpson, Effect of testosterone and estradiol in a man with aromatase deficiency, N Engl J Med 337(2) (1997) 91-95.

[86] Y. Ito, C.R. Fisher, F.A. Conte, M.M. Grumbach, E.R. Simpson, Molecular basis of aromatase deficiency in an adult female with sexual infantilism and polycystic ovaries, Proc Natl Acad Sci U S A 90(24) (1993) 11673-11677.

[87] M.N.R. Velazquez, S. Parween, S.S. Udhane, A.V. Pandey, Variability in human drug metabolizing cytochrome P450 CYP2C9, CYP2C19 and CYP3A5 activities caused by genetic variations in cytochrome P450 oxidoreductase, Biochem Biophys Res Commun 519 (2019) 133-138.

[88] M. Sugishima, H. Sato, K. Wada, K. Yamamoto, Crystal structure of a NADPH-cytochrome P450 oxidoreductase (CYPOR) and heme oxygenase 1 fusion protein implies a conformational change in CYPOR upon NADPH/NADP+ binding, FEBS Letters 593(8) (2019) 868-875.

[89] R. Bernhardt, K. Pommerening, K. Ruckpaul, Modification of Carboxyl Groups on Nadph-Cytochrome-P450 Reductase Involved in Binding of Cytochromes-C and P450 Lm2, Biochem Int 14(5) (1987) 823-832.

[90] R. Bernhardt, R. Kraft, K. Ruckpaul, Molecular Mechanism of Cytochrome-P-450 Reductase Interaction, Cytochrome P-450 : Biochemistry and Biophysics / (1989) 320323.

[91] R. Bernhardt, R. Kraft, A. Otto, K. Ruckpaul, Electrostatic Interactions between Cytochrome-P-450 Lm2 and Nadph-Cytochrome-P-450 Reductase, Biomed Biochim Acta 47(7) (1988) 581-592.
[92] K. Bavishi, D.R. Li, S. Eiersholt, E.N. Hooley, T.C. Petersen, B.L. Moller, N.S. Hatzakis, T. Laursen, Direct observation of multiple conformational states in Cytochrome P450 oxidoreductase and their modulation by membrane environment and ionic strength, Scientific Reports 8 (2018).

[93] J.P. Connick, J.R. Reed, W.L. Backes, Characterization of Interactions Among CYP1A2, CYP2B4, and NADPHcytochrome P450 Reductase: Identification of Specific Protein Complexes, Drug Metabolism and Disposition 46(3) (2018) 197203. 